\title{
Differing Perceptions of the Smartwatch by Users Within Developed Countries
}

\author{
Patricia Baudier, EM Normandie Business School, Le Havre, France \\ (iD) https://orcid.org/0000-0001-9881-4560 \\ Chantal Ammi, Institut Mines Télécom Business School, Evry, France \\ iD https://orcid.org/0000-0001-7942-2633 \\ Samuel Fosso Wamba, Toulouse Business School, Toulouse, France \\ (iD https://orcid.org/0000-0002-1073-058X
}

This article aims to identify differences in the impact of Self-connectivity and the variables of the technological acceptance model (TAM) on smartwatch adoption in developed countries. The countries involved in the data collection were the United States of America, the United Kingdom, Germany, and France. A sample of 1,197 respondents was used. The study identifies distinct adoption behaviours of smartwatch users in these countries and the moderating impacts of age and gender. The study's results confirm that perceived ease-of-use has no impact on attitude-toward-using the smartwatch and its findings emphasize the key role of perceived-connectivity and the moderating effect of culture on the adoption of innovative products.

\section{KEYWORDS}

Acceptance, Innovative Technologies, Internet of Things, Perceived Connectivity, Perceived Playfulness, Smartwatches, TAM, Wearables

\section{INTRODUCTION}

Internet technologies (Zhang, Cai, Le, Fei, \& Ma, 2019) and smart technologies (Maestre-Gongora \& Bernal, 2019), such as the Internet of Things (IoT), are now considered to be part of individuals' dayto-day experience, revolutionizing the ways in which users interact in their personal and professional lives. IOT analytics (2014) splits this market into two categories: business-facing and consumer-facing. For the purposes of this study, the authors focus on the consumer-facing category, segmented into four sub-categories ${ }^{1}$ : home, lifestyle (including wearables), health, and mobility.

With the expansion of the digital era, the use of wearables has grown in popularity in various fields and contexts. Wearables can be defined as smart objects that consumers can wear, such as smartglasses (Rauschnabel, He, \& Ro, 2018), fashionable wearables (Wang, Yu, \& Ma, 2018), or smartwatch devices (Jung, Kim, \& Choi, 2016). As noted by Hsiao and Chen (2018), as wearable computers, smartwatches can facilitate everyday tasks, increase the efficiency of their users, and monitor parameters such as health or wellbeing. Several researchers have analyzed the factors influencing the acceptance of wearable devices (e.g. Kalantari, 2017; Lunney, Cunningham, \& Eastin, 2016). One of

\section{DOI: 10.4018/JGIM.2020100101}

This article, originally published under IGI Global's copyright on September 18, 2020 will proceed with publication as an Open Access article starting on January 13, 2021 in the gold Open Access journal, Journal of Global Information Management (converted to gold Open Access January 1, 2021), and will be distributed under the terms of the Creative Commons Attribution License (http://creativecommons.org/ licenses/by/4.0/) which permits unrestricted use, distribution, and production in any medium, provided the author of the original work and 
the key enablers of smartwatch diffusion relates to the capacity of activity trackers, which offer high potential in the healthcare field (Zhang et al., 2017). As the smartwatch industry produces a greater number of low-cost products, the number of users has inevitably increased. Hence, the economic model for smartwatches is enabling a growth in their adoption around the world. According to Allied Market Research $(2019)^{2}$, in 2017, the smartwatch industry was valued at US\$ 9,264.9 million, and it is forecast to grow to US\$31,070.6 million by 2025 . These products are gaining in popularity, not only because they are economically affordable, but also because of their range of functionalities. As a result, the dynamics of the smartwatch industry have captured the attention of both industry actors and academia. For the purposes of this study, the authors mobilized the technology acceptance model (TAM) (Davis, 1989) as it is a useful approach for understanding technology adoption behaviour in the first wave (early adopters). Perceived-usefulness (PU) and perceived-ease-of-use (PEU), which are the foundations of other robust acceptance models (Venkatesh \& Davis, 2000; Venkatesh, Morris, Davis, \& Davis, 2003; Venkatesh, Thong, \& Xu, 2012), were also deployed, as they have a high capacity for predicting behaviour intention toward determined technology (Davis, 1989). However, while earlier research has extensively used the TAM and its modifications (Choi \& Kim, 2016; Chuah, et al., 2016; Dutot, Bhatiasevi, \& Bellallahom, 2019; Wu, Wu, \& Chang, 2016), the relationship between the TAM variables and perceived-playfulness (PP) and perceived-connectivity (PC) are still to be investigated, as are the moderating impacts of age and gender, as well as the impact of culture, on the use of smartwatches.

The constructs used in this study were chosen on the basis that: (i) the TAM is a popular model frequently used to measure and explain the acceptance of innovative technology (Legris, Ingham, \& Collerette (2003). (ii) TAM is the foundation of other models such as the Unified Theory of Acceptance And Use of Technology (Venkatesh et al. 2003). (iii) the TAM is more accurate if including in a broader model considering human aspects (Legris et al., 2003) such as the perceived connectivity and perceived playfulness. Finally, (iv) TAM is recommended to analyse the early stage of adoption (Davis, 1989).

Thus, the aim of this study is to answer the following research questions: (1) What are the variables impacting (or not) attitude-towards-using a smartwatch? (2) What is the influence of PEU on PU and PP? (3) Does PC influence PU and PEU? (4) Does gender, age, or culture moderate the relationships between the variables explaining ATU?

To address these questions, a research model was built and tested by collecting data from smartwatch users in four developed countries (USA, UK, Germany, and France). According to Market Research Future ${ }^{3}$, the geographical market for the smartwatch is mainly based in North America and Europe, with two key players in Europe, namely Germany and France, where the quality of life and income are higher than in the rest of the world. A cross-national study is recommended because international companies selling the smartwatch, propose quite the same products (shape, features, functionalities, etc.) across countries considering a unified business culture approach (Van Hoorn, 2019). The purpose of this research, through the test of a model based on existing theories, is to identify if variables converge or diverge depending on the country. Indeed, a cross-national study demonstrates if the model is applicable and stable regardless of countries analysed (Craig \& Douglas, 2000). This article is organized as follows. First, the authors present a literature review on the topic of smartwatches and wearables. Second, the variables used to build the model are delineated, followed by a discussion of the hypotheses. Third, the methodology used in the study is explained with findings presented in a results section. Finally, the important practical and theoretical implications of the study, limitations and future research are explored.

\section{THEORY DEVELOPMENT}

User acceptance sheds light on the broader relationships between a user and a given technology. Therefore, understanding the behaviour of users of IT (Gangwar, Date, \& Ramaswamy, 2015; 
Gangwar, Date, \& Raoot, 2014) or IoT technology (Mital, Chang, Choudhary, Papa, \& Pani, 2018), is fundamental, particularly in relation to the influence of various related factors on usage. It is quite clear that organizations that have a deeper understanding of the reasons why their products are accepted and then adopted are able to build an efficient and optimized plan for operating within their network.

In terms of the adoption and use of devices, Jeong, Kim, Park, and Choi (2017) studied domain innovativeness regarding the adoption of wearable devices. The authors' findings emphazised the influence of perceived attributes related to innovations in wearable devices and the purchase intention. Other related literature emphasized the importance of wearable technology in the healthcare context (Zhang, Luo, Nie, \& Zhang, 2017), highlighting the importance of two significant attributes for the adoption of wearable devices: the technical aspect and consumer profile. Lunney et al. (2016), using TAM to measure the acceptability of wearable fitness technology, demonstrated the critical role of perceived health outcomes for the adoption of such technology.

In the smartwatch literature, recent studies have pointed out the importance of understanding the intention to adopt (Choi \& Kim, 2016; Chuah et al., 2016; Dutot et al., 2019; Wu et al., 2016; Baba, Baharudin, \& Alomari, 2019), whereby the authors develop an integrative model based on welldiffused constructs. This strategy, providing the robustness of the model and ensuring reliability, has been successfully used in other studies (Dutot et al., 2019; Hsiao \& Chen, 2018). For instance, Hsiao and Chen (2018) integrated different constructs related to perceived value, appearance, hardware, and software. Along the same lines, Dutot et al. (2019) integrated TAM and Perceived Affective Quality with other constructs. Also, Wu et al. (2016) integrated TAM with the unified theory of acceptance and use of technology, innovation diffusion theory, and used TAM with the inclusion of the visibility construct (Chuah et al., 2016). Previous studies highlighted the need to incorporate moderating factors in an integrative model (Choi \& Kim, 2016; Dutot et al., 2019). In this regard, the literature concerning the relationship of TAM to other variables, such as control variables like gender, was necessary (Dutot et al., 2019; Wu et al., 2016). In addition, there is a lively debate about whether gender affects intention to adopt the smartwatch (Chuah et al., 2016; Dutot et al., 2019). The value and importance of a number of variables are being discussed and established in the smartwatch adoption literature. For example, Chuah et al. (2016) report that PU and visibility influence smartwatch adoption. In another study, concerning the intention to adopt smartwatches, Wu et al; (2016) showed no significant effect on ease of use, but discovered that gender had no influence on the intention to adopt. More recently, Dutot et al. (2019) applied a model based on TAM, perceived affective quality, and other constructs like trust, mobility, and availability in three countries (China, France, and Thailand.) The authors reported that there are substantial differences between countries and gender in the adoption of smartwatches. Some studies measure the impact on Intention To Use a smartwatch of (1) design, size, and uniqueness (Dehghani \& Kim, 2019), (2) emotional or functional communications (Krey, Chuah, \& Ramayah, 2019), (3) hardware/software benefits combined with values (Hsiao \& Chen, 2018), or (4) mediation model (Chuah, 2019).

\section{Attitude Towards Using (ATU)}

According to the TAM, the ATU is a dependent variable measuring the positive or negative valence of individuals regarding the use of a technology (Davis, 1989; Davis et al., 1989), determined by two independent constructs: perceived-ease-of-use and perceived-usefulness.

\section{Perceived-Ease-of-Use (PEU)}

PEU refers to the feelings of an individual in terms of whether the use of a technological system is viewed as being free from effort (Davis et al., 1989; Venkatesh \& Davis, 2000) and how readily an individual can become skilful at using this technology. PEU is a huge predictor of ATU digital technology (Kabbiri, Dorac, Kumard, Elepue, \& Gellynck, 2017). Mital et al. (2018) argue that PEU has a positive influence on users' attitude regarding IoT adoption. The easier an individual perceives 
smartwatch usage to be, the more positively the individual will view the device and have a positive Attitude-towards-Using it. Building on previous research, the authors suggest that:

Hypothesis One: PEU has a direct, positive, and significant impact on ATU.

Perceived-usefulness (PU) measures to what degree the use of a technology is perceived as improving personal or professional performance (Venkatesh \& Davis, 2000), allowing users to perform by completing tasks in time, increasing their efficiency and productivity. The authors redefine the PU of smartwatches as the extent to which a consumer believes that using a smartwatch increases his or her personal efficiency, such as being more organized and more productive. (Kulviwat, Bruner, Kumar, Nasco, \& Clark, 2007). TAM suggests that technologies are perceived as more useful when they are easier to use. Several studies confirm the significant and positive relationships between PEU and PU (Chuah et al., 2016; Liu \& Yu, 2017). For the purposes of this research, the more users consider the smartwatch as easy to use, the more they find it useful. Perceived-playfulness (PP) is related to PEU, as customers are more likely to use an innovation if they find it simple to use and enjoyable (Davis et al., 1989). Fosso-Wamba et al. (2017) validate this positive relation for social media acceptance in workspaces and Kabbiri et al. (2017) for mobile phones. Thus, the authors postulate that:

Hypothesis Two: PEU has a direct, positive, and significant relationship with PU.

Hypothesis Three: PEU has a direct, positive, and significant relationship with PP

\section{Perceived-Usefulness (PU) on ATU}

Considered to be one of the two main variables of the TAM (Davis, 1989), PU is an extrinsic motivator considered as an influential antecedent of the acceptance of new technology. PU is defined as "The degree to which a person believes that using a particular system would enhance his or her job performance" (Davis, 1989, p. 320). Mital et al. (2018) confirm the impact of PU on attitude regarding the adoption of IoT. Similarly, Wang and Sun (2016) propose a positive relationship between PU and "attitude" in relation to the adoption of gameplay by the elderly. In line with previous studies, the authors hypothesize that:

\section{Hypothesis Four: PU has a direct, positive, and significant impact on ATU}

\section{Perceived-Playfulness (PP)}

The pleasure to use smartwatches is not simply derived from owning a well-designed watch but from other factors, including entertainment value. Hence, a deeper level of analysis is required to capture the perceived-playfulness construct. Playfulness focuses on hedonic motivation and is a key feature of social relationships. PP measures customer perceptions during their interaction with, for example, digital solutions based on their focus of attention, their curiosity level, and whether the interaction is perceived as enjoyable and interesting (Moon \& Kim, 2001). Research on websites (Moon \& Kim, 2001) or social networking sites (Chang, Hung, Cheng, \& Wu, 2015) suggests that PP could positively impact ATU. Indeed, PP is crucial for the adoption of digital solutions such as information searching websites (Chun \& Tan, 2004) or instant messaging (Luo, Gurung, \& Shim, 2010). In line with previous studies, the authors hypothesize that:

Hypothesis Five: PP has a positive, significant, and direct effect on ATU 


\section{Perceived-Connectivity (PC)}

According to Venkatesh et al. (2003), social-influence measures an individual's perception of the influence of others when it comes to adopting a new technology. The Theory-of-Reasoned-Action demonstrates the influence of subjective norms and attitudes on individuals' behaviour. Based on Rogers (2003), "diffusion-of-innovation" success is directly linked to the number of individuals using the innovative technology; the more people use it, the more the interest and acceptance level of new technology will increase. According to Luo, Gurung, and Shim (2010), one of the determinants of user acceptance is perceived-connectivity (PC), which measures the number of people, such as family, colleagues, or friends, who also use the same technology. PC has a huge influence on the acceptance of digital technologies (Strader, Ramaswami, \& Houle, 2007). Indeed, the level of adoption of a technology by others, especially close relatives or friends, can influence user acceptance. Lou, Luo, and Strong (2001) highlight the importance of a critical mass of users, resulting in potential interconnections and leading to adoption. This phenomenon is not new. Katz and Shapiro (1986) found that acceptance of technology is directly linked to the numbers of users, for example, of communication technologies. It is clear that the perceived number of users, such as colleagues, friends, or family, will impact the perceived value of a technology being used (Strader et al., 2007). In fact, PC directly influences PEU and PU (Luo et al. (2010). These results are confirmed by Fosso-Wamba and Akter (2016), who found that PC impacts directly and positively on the ATU social media. Thus, the authors propose the following hypotheses:

Hypothesis Six: $P C$ has a direct, positive, and significant impact on $P U$.

Hypothesis Seven: $P C$ has a direct, positive, and significant impact on PEU.

Hypothesis Eight: $P C$ has a direct, positive, and significant impact on ATU.

\section{Moderating Effects}

\section{Gender}

A user's gender can be decisive for technology acceptance (Gefen \& Straub, 1997) and its influence should not be disregarded. Many studies have measured the moderating effect of gender on new technology adoption (e.g. Leong, Ooi, Chong, \& Lin, 2013). Venkatesh and Morris (2000) confirm that females' adoption of new technologies is more influenced by PEU whereas males are more influenced by PU. Several studies demonstrate the moderating effect of gender on PP (e.g. Rodríguez-Ardura $\&$ Meseguer-Artola, 2018). However, attitudes toward using a smartwatch (usefulness, ease-of-use, perceived-playfulness) are very similar regardless of gender, as the level of technology is more or less identical to Smartphone technology (Pechtelidis, Kosma, \& Chronaki, 2015). In addition, many authors found that gender had no influence on adoption (e.g. Leong et al., 2013).

\section{Age}

Researchers have frequently analyzed the influence of age on individual behaviour and include it as a moderator of relationships in the TAM (Chung, Park, Wang, Fulk, \& McLaughlin, 2010). The elderly are considered to have less propensity than the younger generation to adopt innovative products. In terms of PC, older users are more impacted by the behaviour of others (Sun \& Zhang, 2006), especially if others confirm ease-of-use (Chung et al., 2010). Wagner, Hassanein, and Head (2010) find a direct relationship between advanced age and negative attitudes to innovations. A number of researchers have measured the moderating effect of age on PEU (e.g. Liébana-Cabanillas, Sanchez-Fernandez, \& Munoz-Leiva, 2014), emphasizing the fact that PEU is key for the older generation, who are not typically confident in their use of innovative technology. Several empirical studies have concluded that young people integrate mobile phones into their daily lives while older people generally use them as a symbol of social status and for basic functions, which is also the case for the smartwatch (Skog, 2002). Finally, based on TAM, age influences the adoption of innovative technology. 


\section{Country}

The purpose of this study was also to analyze the impact of country on the acceptance of innovative products (Khan, Hameed, \& Khan, 2017; Changchit, Lonkani, \& Sampet, 2018). McCoy, Galletta, and King (2007), having analyzed 20 countries, recommend considering the influence of culture when using TAM. Kim, Urunov, and Kim (2016) demonstrate the direct and significant impact of culture on PU, PEU, and Intention-to-Use.

All hypotheses are summarized in the research model (Figure 1).

Figure 1. Research Model

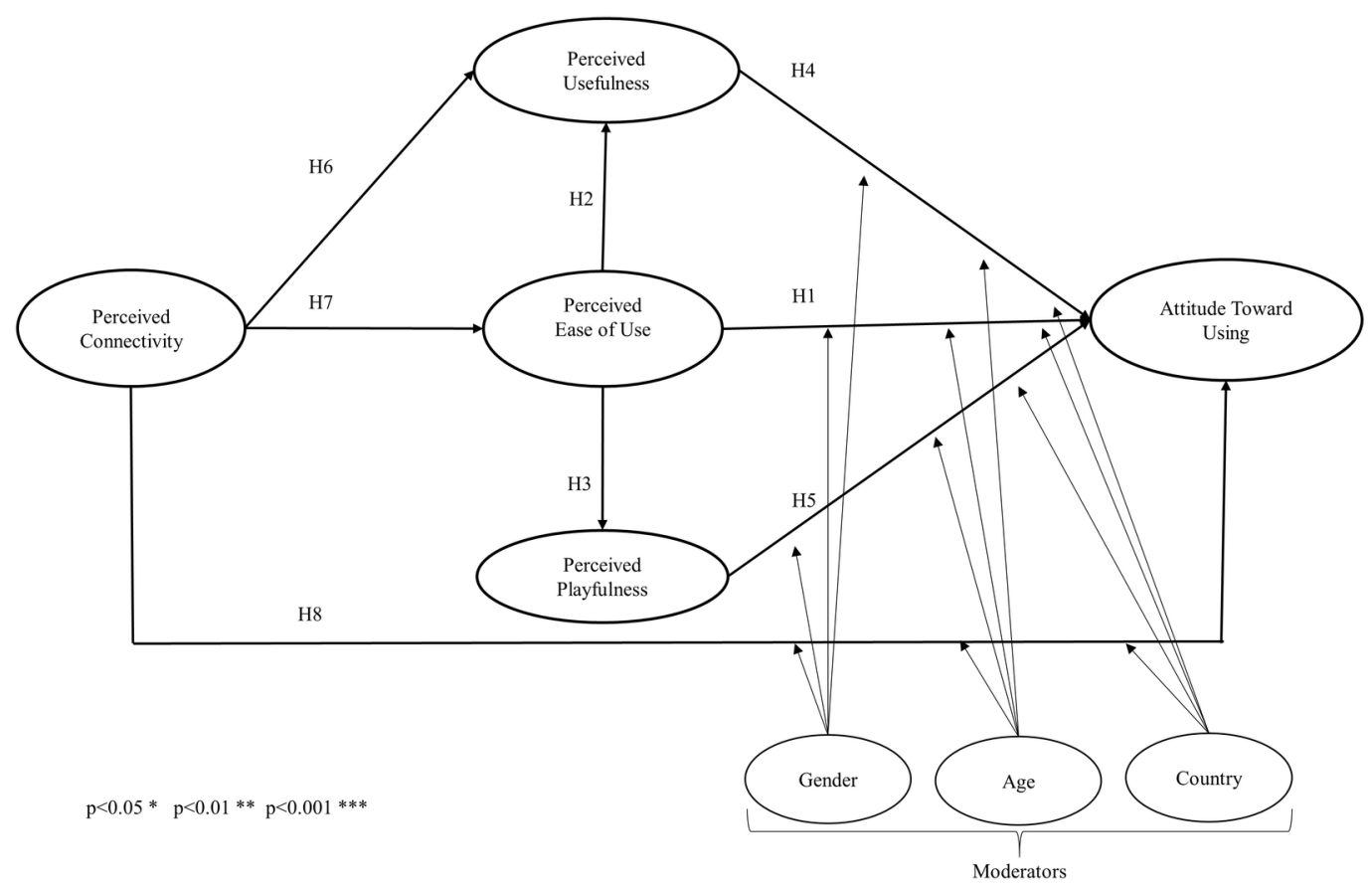

\section{DATA COLLECTION}

This study uses a cross-sectional survey design approach to test the authors' hypotheses (Appendix A). Based on an intensive literature review, a web-based survey was created for data collection from smartwatch owners and users in four developed countries: UK, USA, Germany, and France. According to Reynolds, Simintiras, and Diamantopoulos (2003), when the research objective is to examine at a cross national level if the model can be generalized, a non-probability approach is acceptable. The data collection process, carried out from $7^{\text {th }}$ to $31^{\text {st }}$ May 2017, was conducted by a leading market research provider, Survey Sampling International (SSI), using its panels. An invitation describing the objective of the study was sent to all panel members owning a smartwatch. In response to this invitation, 2,365 panel members agreed to participate in the study. At the end of the data collection process, 1,197 valid questionnaires (297 in Germany \& UK, 300 in France, and 303 in the USA) had been received which were fully completed and suitable for further analysis, providing a response rate of 51\%. Items (see Appendix A) derived from prior studies were adapted to our research setting using a 7-point Likert scale, from strongly-disagree (1) to strongly-agree (7), to measure the following: perceived-usefulness, perceived-ease-of-use, and attitude-towards-using (Davis, 1989), Perceived- 
Playfulness (Moon \& Kim, 2011), and finally Perceived-Connectivity (Luo, Gurung, \& Shim, 2010). The questionnaire was created in English and translated into German and French and then proofread by foreign researchers, including both the American and UK versions, and a final check was conducted using SSI. As regards the sample characteristics (see Appendix B), men represent 53 per cent of respondents in the UK, 52 percent in France, and 51 per cent in the USA; in Germany, men and women are equally represented (50\%). In all countries, the majority of respondents were less than 35 years old (58-62\%), lived in cities with more than 50,000 residents (53-60\%), with a fulltime job (61-75\%), mainly with management responsibilities (53-56\%), except in the USA, where the occupational categories differed more widely, as smartwatch ownership is more widely distributed through all strata of the population. Between 61-71 per cent bought themselves their smartwatch, had used it for less than six months (55-66\%) and used it several times per day (92-93\%).

\section{RESULTS}

The reliability of the model was controlled: The Cronbach's Alpha and the loading of each item were above the recommended threshold of 0.7 (Appendix A). The authors achieved convergent validity by verifying that the average-value-extracted of each value reached the minimum threshold recommended of 0.5 (Appendix A). The discriminant validity was verified by checking the cross-loading values and by controlling that the square roots of the average-value-extracted of the construct were superior to the correlations of this variable with the other variables (Appendix C). Our evaluation confirms the validity and reliability of the outer model.

The $\mathrm{R}^{2}, \mathrm{f}^{2}$, and $\mathrm{Q}^{2}$ of the constructs were verified to test the inner model. Several parameters were used to evaluate the relationships between variables such as path coefficient (PCo $>$ at 0.200 ), $t$-value ( $>$ at 1.96), and $\mathrm{p}$-value $\left(<\right.$ at 0.05 ). The explained variances $\left(\mathrm{R}^{2}\right)$ of the endogenous variables were examined. Our model explains 48.2 percent of ATU determined by PU (H4), PP (H5), PC (H8), and PEU (H1). The size effects $\mathrm{f}^{2}$ of PEU, PU, and PC are considered to be low and are moderated for PP. The $\mathrm{R}^{2}(0.524)$ shows that the model explains a significant amount of the variance of PU determined by two constructs: PEU (H6) and PC (H2). Both variables, with a $\mathrm{f}^{2}$ at 0.234 (PC) and 0.584 (PEU), have a huge size effect on PU. PC only explains 7.4 per cent of PEU (H7) with a low effect $\left(\mathrm{f}^{2}=\right.$ 0.08). Finally, the $\mathrm{R}^{2}$ of $P P$ at 28.7 per cent is explained by PEU $(H 3)$. The $f^{2}(0.402)$ confirms the significant impact of PEU on PP. A blindfolding procedure was run to control the Stone-Geisser's $\mathrm{Q}^{2}$. Values were all above 0 with a better predictive relevance for ATU (0.372) and PU (0.326). The quality of the hypothetical model is both confirmed by standardized-root-mean-square-residual at 0.047 , below the recommended threshold of 0.1 , and by "Normed-Fit-Index" at 0.91 above the acceptable fit of 0.9. Results confirmed that the model is free of common method bias as all variance inflation factors are below the recommended threshold of 3.3 (Appendix D).

Finally, as indicated in Table 1, all hypotheses are validated for the global model ( $\mathrm{S}=$ Supported).

\section{Moderating Effects}

To control the moderating effects of gender, age, and country on the variables explaining attitudetowards-using (ATU), the multi-group-analysis procedure of SmartPLS3 software was used, highlighting the significant differences within each group. The variability of the Path Coefficients, the $t$ and $p$-values, were analyzed using the Bootstrapping procedure.

\section{Gender}

Findings confirmed that gender has no impact on the relationship of PC, PP, and PU on ATU. Nevertheless, a positive, direct, and significant impact for females was highlighted for the relationship between PEU and ATU, whereas the impact is not significant for males. 
Table 1. Test of hypotheses

\begin{tabular}{|l|l|l|l|l|l|l|l|l|}
\hline Construct & $\begin{array}{l}\text { Predictor } \\
\text { variable }\end{array}$ & \multicolumn{1}{|c|}{$\mathbf{R}^{2}$} & $\mathbf{f}^{2}$ & PCo & t-Value & p-Value & $\mathbf{Q}^{2}$ & H \\
\hline ATU & & 0.482 & & & & & 0.372 & \\
\hline & PP & & 0.099 & 0.320 & 9.350 & 0.000 & & S \\
\hline & PC & & 0.047 & 0.180 & 6.977 & 0.000 & & S \\
\hline & PEU & & 0.007 & 0.080 & 2.301 & 0.021 & & S \\
\hline & PU & & 0.050 & 0.264 & 6.695 & 0.000 & & S \\
\hline PU & & 0.524 & & & & & 0.326 & \\
\hline & PC & & 0.234 & 0.347 & 14.794 & 0.000 & & S \\
\hline & PEU & & 0.584 & 0.548 & 22.578 & 0.000 & & S \\
\hline PEU & & 0.074 & & & & & 0.052 & \\
\hline & PC & & 0.080 & 0.272 & 10.069 & 0.000 & & S \\
\hline PP & & 0.287 & & & & & 0.198 & \\
\hline & PEU & & 0.402 & 0.536 & 18.684 & 0.000 & & S \\
\hline
\end{tabular}

\section{Age}

No major differences were found regarding the impact of age on the relationships of PP and PU on ATU. Nevertheless, differences are highlighted for the impact of PC and PEU on ATU, as results for respondents between 41-50 years old for PC and 31-40 years old for PEU differ from the other age ranges.

\section{Country}

One of the purposes of this study was to highlight potential differences regarding the acceptability of the smartwatch according to the country of origin. The impacts of PC and PP on ATU are positive and significant across all countries. Nevertheless, PEU has a positive impact only in the case of the two Anglo-Saxon countries: the UK and USA. The impact of PU on ATU is positive for all countries except for the USA.

\section{DISCUSSION AND CONCLUSION}

This study aims to shed light on the perceptions of smartwatch owners. The purpose is (1) to discover the effect of variables explaining ATU, (2) to check the potential influence of PEU on PU and PP, (3) to validate the impact of PC on PU and PEU and, finally, (4) to analyze the moderating effects of gender, age, and culture on the variables explaining ATU. (1) Results confirmed the impact of PEU on ATU. Nevertheless, the size effect is considered to be low and the Path Coefficient is below the recommended threshold of 0.200. Kabbiri et al. (2017) highlight the huge impact of PEU on the adoption of mobile phones, whereas Liu and Yu's (2017) study finds no impact of PEU on the acceptance of Smartphones. Chuah et al. (2016) find that this relation is not significant in the context of wearables, contradicting the study done by Mital et al. (2018) on IoT adoption. Second, according to prior information systems research, the utilitarian feature (PU) is the strongest determinant of IS acceptance directly impacting the ATU. Kim and Shin (2015) highlight the finding that the PU of the smartwatch can differ according to whether users consider it as a useful technology or as a fashion accessory. Respondents confirmed the perception of the usefulness of the smartwatch. The authors' findings are consistent with previous research on IoT's (Mital et al., 2018) and wearable 
technologies (Chuah et al., 2016). Third, the authors' findings, reinforcing the importance of the PP construct on ATU, are aligned with previous research (Lin, Wu, \& Tsai, 2005; Strader et al., 2007; Fosso-Wamba \& Akter, 2016), confirming that the adoption and effective use of the technology by a critical mass of users can have a positive impact on users' behaviour. (2) The authors' findings reinforce the influence of the PEU and confirm its strong effect on PU (Venkatesh et al., 2003; Wang $\&$ Sun, 2016; Chuah et al., 2016). The relation between PEU and PP is strong, and these findings are aligned with other studies (e.g. Moon \& Kim, 2001). (3) Few studies use the construct of PC, and most of them focus on professional behaviours and not on individuals (Luo et al., 2010). Respondents confirm that more than 35 per cent of their colleagues, 46 per cent of their friends, and 40 per cent of their family members use a smartwatch. These percentages confirm the high degree of connectivity of the respondents near environment. Indeed, when smartwatch users notice that others are using the same technology, they can easily and quickly access information/support. The findings demonstrate the direct impact of PC on PU and PEU confirming a previous study (Luo et al., 2010). (4) No differences were found in the impact of PC, PP, and PU on ATU on the moderating effect of gender. Some studies have already introduced a gender perspective when testing the TAM, and their findings confirm no gender impacts (Arruda-Filhoa, Cabusas, \& Dholakia, 2010). This lack of moderating effect of gender can be explained by the fact that smartwatches look like traditional watches (Wu et al., 2016) and work in the same way as a Smartphone, explaining their acceptance by both genders in terms of connectivity, usefulness, and playfulness. However, the impact of PEU on ATU is rejected by males and validated by females. The authors' results are aligned with Terzis and Economides' (2011) study on computer-based assessment. Indeed, PEU is more salient for females than for males (Wang \& Sun, 2016). This finding confirms results published by other researchers (e.g. Hur, Kim, \& Kim, 2012). In conclusion, even though smartwatches work in the same way as the smartphone, PEU is considered by females as key. As regards the age of the respondent, no major differences were highlighted for the impact between PP and PU on ATU. This result contradicts the fact that younger users are usually more sensitive to Enjoyment than older ones and that younger users are less sensitive to Usability. Nevertheless, smartwatch users are today considered as early adopters, sharing similar perceptions regarding the product regardless of age. Previous results confirm that the relation between PP and ATU is not moderated by age for the acceptance of wearables (Wu et al., 2016). Thus, the authors' findings are consistent. However, the relationship of PC with ATU was rejected by the 41 to 50 years old category. These respondents, considered as "digital immigrants", born before 1981, do not necessarily have technologically skilled peers. The first explanation could be that their friends in the same age group are not necessarily equipped and their children are too young to convince them to adopt this new technology. Nevertheless, the fact that their peers cannot provide them with support seems not to be an issue, confirming their profile as early adopters. The relation between PEU and ATU is positive for respondents aged between 31-40 years old but rejected for all other age groups. This finding is consistent with a study done on the adoption of mobile health services (Zhao \& Zhou, 2018), where PEU is perceived as more important for the middleaged population. The aim of the current study is to consider the potential differences between the Western countries selected. The results confirm that the impacts of PC and PP on ATU are positive and significant across all countries. However, there are some important differences. Findings confirm that the impact of PU on ATU is validated for the UK, Germany, and France but not for the USA. This could be explained by the respondents' profiles, given that most US respondents did not have management responsibilities and the questions measuring the utilitarian construct were more focused on their professional activities (useful for their job, improving their productivity, etc.). In addition, Choi and Totten (2012) demonstrate that the impact of PU on the adoption of mobile TV is less important in the USA than in South Korea. Finally, the research also confirms that the relationship between PEU and ATU is not validated for France and Germany, but the authors did find an impact for the UK and USA. Several researchers have analyzed the impact of culture on PEU (McCoy et al., 2007) and this study's results are aligned with a previous study published by Smith et al. (2013) 
on online shopping in Germany, USA, and Norway. Rufin, Belanger, Molina, Carter, and Figueroa (2014) confirm the effect of PEU on technology adoption in the USA, whereas this relationship is not confirmed in Spain. Finally, our results confirm the analysis done by Hofstede (1989), in which the UK and USA receive similar scores when compared to other countries with different cultures.

\section{Theoretical And Managerial Implications, Limitations, And Future Research}

This study has important implications for both academics and managers in the information systems field and especially in the domain of wearable devices. One of its theoretical contributions is the investigation of smartwatch use from a cultural perspective. Based on a survey by Childlow, Ghauri, Yeniyurt and Cavusgil (2015) of 285 articles, only 5.78 per cent extended their research to four countries. Therefore, our study contributes to improving knowledge regarding the cross-national analysis. Furthermore, this research represents a contribution to existing knowledge on the field of technology acceptance, as the researchers address a gap in the literature by integrating two human aspects' variables into the TAM: "Perceived-Connectivity" and "Perceived Playfulness" when measuring the level of acceptance of the smartwatch. In addition, the study's results highlight the role of culture, gender, and age as moderators and emphasize the importance of integrating them when studying the acceptance of technology. Finally, this research confirms the reliability and accuracy of the model proposed and its relevance when analysing different countries.

The practical implications of the study will be of benefit to those who manage and promote wearable devices such as smartwatches. The statistical results support the crucial role of the utilitarian and hedonic functionalities of the smartwatch. Thus, managers should, when communicating information about the smartwatch, focus on its usefulness and playfulness aspects rather than easeof-use. Indeed, results confirm the lower impact of perceived-ease-of-use for the smartwatch maybe because considered as an extension of the smartphone. In addition, the results suggest that managers should consider the importance of perceived-connectivity and therefore develop and maintain a close link with early adopters or influencers. Indeed, these users contribute to spreading positive feedback on products and increase the potential rate of adoption. Finally, due to the consistency of results across countries analysed, this research confirms the accuracy of an international business approach for such products. In addition, the findings show that moderators such as age and gender have only a minor impact, emphasizing the fact that, at an early adopter stage, managers do not necessarily need to consider them. In addition, culture does not really impact on the relationships of the model, confirming that international corporations might standardize their products without being obliged to adapt them to local culture.

This study has several limitations. First, the authors focus on unbranded products, and the results could have been impacted by brand attachment/brand love and also by the relationship between consumer attitudes and brand identification. Second, the study focuses on occidental and developed countries (France, Germany, UK, and USA), but the Asian continent (third region for the smartwatches market ${ }^{4}$ ) and the rest of the world including developing countries, in general, are not represented. Finally, only two constructs measuring the human aspects have been integrated into the TAM (Playfulness and Connectivity). Thus, any future studies should replicate the model with users of a specific brand, conduct a longitudinal analysis to measure the evolution of the impact of PC on the model, extend the study to Asian and or developing countries and analyse other human aspect variables such as trust for example.

\section{ACKNOWLEDGMENT}

This research was supported by Survey Sampling International (Survey sample) 


\section{REFERENCES}

Arruda-Filhoa, E. J. M., Cabusas, J. A., \& Dholakia, N. (2010). Social behavior and brand devotion among iPhone innovators. International Journal of Information Management, 30(6), 475-480. doi:10.1016/j. ijinfomgt.2010.03.003

Baba, N. M., Baharudin, A. S., \& Alomari, S. (2019). Determinants of user's intention to use smartwatch. Journal of Theoretical and Applied Information Technology, 97(18), 4738-4750.

Chang, C.-C., Hung, S.-W., Cheng, M.-J., \& Wu, C.-Y. (2015). Exploring the intention to continue using social networking sites: The case of Facebook. Technological Forecasting and Social Change, 95, 48-56. doi:10.1016/j. techfore.2014.03.012

Changchit, C., Lonkani, R., \& Sampet, J. (2018). Determinants of Mobile Banking Adoption: A comparative study between U.S. and Thailand. Journal of Global Information Management, 26(4), 158-184. doi:10.4018/ JGIM.2018100109

Childlow, A., Ghauri, P. N., Yeniyurt, S., \& Cavusgil, S. T. (2015). Establishing rigor in mail-survey procedures in international business research. Journal of World Business, 50(1), 26-35. doi:10.1016/j.jwb.2014.01.004

Choi, J., \& Kim, S. (2016). Is the smartwatch an IT product or a fashion product? A study on factors affecting the intention to use smartwatches. Computers in Human Behavior, 63, 777-786. doi:10.1016/j.chb.2016.06.007

Choi, Y. K., \& Totten, J. W. (2012). Self-construal's role in mobile TV acceptance: Extension of TAM across cultures. Journal of Business Research, 65(11), 1525-1533. doi:10.1016/j.jbusres.2011.02.036

Chuah, S. H.-W. (2019). You inspire me and make my life better: Investigating a multiple sequential mediation model of smartwatch continuance intention. Telematics and Informatics, 43, 101245. doi:10.1016/j. tele.2019.101245

Chuah, S. H.-W., Rauschnabel, P. A., Krey, N., Nguyen, B., Ramayah, T., \& Lade, S. (2016). Wearable technologies: The role of usefulness and visibility in smartwatch adoption. Computers in Human Behavior, 65, 276-284. doi:10.1016/j.chb.2016.07.047

Chung, J., \& Tan, F. B. (2004). Antecedents of perceived playfulness: An exploratory study on user acceptance of general information-searching websites. Information \& Management, 41(7), 869-991. doi:10.1016/j. im.2003.08.016

Chung, J. E., Park, N., Wang, H., Fulk, J., \& McLaughlin, M. (2010). Age differences in perceptions of online community participation among non-users: An extension of the Technology Acceptance Model. Computers in Human Behavior, 26(6), 1674-1684. doi:10.1016/j.chb.2010.06.016

Craig, C. S., \& Douglas, S. P. (2000). International Marketing Research (2nd ed.). New York: Wiley.

Davis, F. D. (1989). Perceived usefulness, perceived ease of use, and user acceptance of information technology. Management Information Systems Quarterly, 13(3), 319-340. doi:10.2307/249008

Davis, F. D., Bagozzi, R., \& Warshaw, P. R. (1989). User Cacceptance of Computer Technology: A comparaison of Two Theoretical Models. Management Science, 35(8), 982-1003. doi:10.1287/mnsc.35.8.982

Dehghani, M., \& Kim, K. J. (2019). The effects of design, size, and uniqueness of smartwatches: Perspectives from current versus potential users. Behaviour \& Information Technology, 38(11), 1143-1153. doi:10.1080/0 144929X.2019.1571111

Dutot, V., Bhatiasevi, V., \& Bellallahom, N. (2019). Applying the technology acceptance model in a threecountries study of smartwatch adoption. The Journal of High Technology Management Research, 30(1), 1-14. doi:10.1016/j.hitech.2019.02.001

Fosso-Wamba, S., Bhattacharya, M., Trinchera, L., \& Ngai, E. W. T. (2017). Role of intrinsic and extrinsic factors in user social media acceptance within workspace: Assessing unobserved heterogeneity. International Journal of Information Management, 37(2), 1-13. doi:10.1016/j.ijinfomgt.2016.11.004

Fosso-Wamba, S., \& Akter, S. (2016). Impact of Perceived Connectivity on Intention to Use Social Media: Modelling the Moderation Effects of Perceived Risk and Security. doi:10.1007/978-3-319-45234-0_20 
Gangwar, H., Date, H., \& Raoot, A. D. (2014). Review on IT adoption: Insights from recent technologies. Journal of Enterprise Information Management, 27(4), 488-502. doi:10.1108/JEIM-08-2012-0047Gangwar, H., Date, H., \& Ramaswamy, R. (2015). Understanding determinants of cloud computing adoption using an integrated TAM-TOE model. Journal of Enterprise Information Management, 28(1), 1-31. doi:10.1108/JEIM-08-2013-0065

Gefen, D., \& Straub, D. (1997). Gender Differences in the Perception and Use of E-Mail: An Extension to the Technology Acceptance Model. Management Information Systems Quarterly, 21(4), 389-400. doi:10.2307/249720

Ha, S., \& Stoel, L. (2009). Consumer e-shopping acceptance: Antecedents in a technology acceptance model. Journal of Business Research, 62(5), 565-571. doi:10.1016/j.jbusres.2008.06.016

Hofstede, G. (1989). Organising for cultural Diversity. European Management Journal, 7(4), 390-397. doi:10.1016/0263-2373(89)90075-3

Hsiao, K. L., \& Chen, C. C. (2018). What drives smartwatch purchase intention? Perspectives from hardware, software, design, and value? Telematics and Informatics, 35(1), 103-113. doi:10.1016/j.tele.2017.10.002

Hur, W.-M., Kim, H., \& Kim, W.-M. (2014). The moderating role of gender and age in Tablet adoption. Cyberpsychology, Behavior, and Social Networking, 17(1), 33-39. doi:10.1089/cyber.2012.0435 PMID:23962126

Jeong, S. C., Kim, S. H., Park, J. Y., \& Choi, B. (2017). Domain-specific innovativeness and new product adoption: A case of wearable devices. Telematics and Informatics, 34(5), 399-412. doi:10.1016/j.tele.2016.09.001

Jung, Y., Kim, S., \& Choi, B. (2016). Consumer valuation of the wearables : The case of smartwatches. Computers in Human Behavior, 63, 899-905. doi:10.1016/j.chb.2016.06.040

Kabbiri, R., Dorac, M., Kumard, V., Elepue, G., \& Gellynck, X. (2017). Mobile phone adoption in agri-food sector: Are farmers in Sub-Saharan Africa connected? Technological Forecasting and Social Change. doi:10.1016/j. techfore.2017.12.010

Kalantari, M. (2017). Consumers' adoption of wearable technologies: Literature review, synthesis, and future research agenda. International Journal Technology Marketing, 12(3), 274-30. doi:10.1504/IJTMKT.2017.089665

Katz, M. L., \& Shapiro, C. (1986). Technology adoption in the presence of network externalities. Journal of Political Economy, 94(4), 822-841. doi:10.1086/261409

Khan, I. U., Hameed, Z., \& Khan, S. U. (2017). Understanding Online Banking Adoption in a Developing country: UTUAT2 with cultural Moderators. Journal of Global Information Management, 25(1), 43-65. doi:10.4018/ JGIM.2017010103

Kim, E., Urunov, R., \& Kim, H. (2016). The effects of national culture values on consumer acceptance of e-commerce: Online shoppers in Russia. Information Technology and Quantitative Management, 91, 966-970.

Kim, M. Y., \& Park, B. I. (2017). The impact of country of origin on context effects in choice. International Marketing Review, 34(6), 706-734. doi:10.1108/IMR-03-2015-0074

Kim, K. J., \& Shin, D.-H. (2015). An acceptance model for smart watches: Implications for the adoption of future wearable technology. Internet Research, 25(4), 527-541. doi:10.1108/IntR-05-2014-0126

Krey, N., Chuah, S. H.-W., Ramayah, T., \& Rauschnabel, P. A. (2019). How functional and emotional ads drive smartwatch adoption: The moderating role of consumer innovativeness and extraversion. Internet Research, 29(3), 578-602. doi:10.1108/IntR-12-2017-0534

Kulviwat, S., Bruner, G. C. II, Kumar, A., Nasco, S. A., \& Clark, T. (2007). Toward a unified theory of consumer acceptance technology. Psychology and Marketing, 24(12), 1059-1084. doi:10.1002/mar.20196

Lee, J., Kim, J., \& Choi, J. Y. (2019). The adoption of virtual reality devices: The technology acceptance model integrating enjoyment, social interaction, and strength of the social ties. Telematics and Informatics, 39, 37-48. doi:10.1016/j.tele.2018.12.006

Legris, P., Ingham, J., \& Collerette, P. (2003). Why do people use information technology? A critical review of the tevhnology acceptance model. Information \& Management, 40(3), 191-204. doi:10.1016/S0378-7206(01)00143-4 
Leong, V., Ooi, K.-B., Chong, A. Y.-L., \& Lin, B. (2013). Modeling the stimulators of the behavioral intention to use mobile entertainment: Does gender really matter? Computers in Human Behavior, 29(5), 2109-2121. doi:10.1016/j.chb.2013.04.004

Liébana-Cabanillas, F., Sanchez-Fernandez, J., \& Munoz-Leiva, F. (2014). Antecedents of the adoption of the new mobile payment systems: The moderating effect of age. Computers in Human Behavior, 35, 464-478. doi:10.1016/j.chb.2014.03.022

Lin, C. S., Wu, S., \& Tsai, R. J. (2005). Integrating perceived playfulness into expectation-confirmation model for Web portal context. Information \& Management, 42(5), 683-693. doi:10.1016/j.im.2004.04.003

Liu, N., \& Yu, R. (2017). Identifying design feature factors critical to acceptance and usage behavior of smartphones. Computers in Human Behavior, 70, 131-142. doi:10.1016/j.chb.2016.12.073

Lunney, A., Cunningham, N. R., \& Eastin, M. S. (2016). Wearable fitness technology: A structural investigation into acceptance and perceived fitness outcomes. Computers in Human Behavior, 65, 114-120. doi:10.1016/j. chb.2016.08.007

Lou, H., Luo, W., \& Strong, D. (2001). Perceived critical mass effect on groupware acceptance. European Journal of Information Systems, 9(2), 91-103. doi:10.1057/palgrave.ejis.3000358

Luo, X., Gurung, A., \& Shim, J. P. (2010). Understanding the Determinants of User Acceptance of Enterprise Instant Messaging: An Empirical Study. Journal of Organizational Computing and Electronic Commerce, 20(2), 155-181. doi:10.1080/10919391003709179

Maestre-Gongora, G. P., \& Bernal, W. N. (2019). Conceptual Model of Information Technology Management for Smart cities: SmartTICity. Journal of Global Information Management, 27(2), 159-175. doi:10.4018/ JGIM.2019040109

McCoy, S., Galletta, F. D., \& King, R. W. (2007). Applying TAM across cultures: The need for caution. European Journal of Information Systems, 16(1), 81-90. doi:10.1057/palgrave.ejis.3000659

Mital, M., Choudhary, P., Chang, V., Papa, A., \& Pani, A. K. (2018). Adoption of Internet of Things in India: A test of competing models using a structured equation modeling approach. Technological Forecasting and Social Change, 136, 339-346. doi:10.1016/j.techfore.2017.03.001

Moon, J. W., \& Kim, Y. G. (2001). Extending the TAM for a World-Wide-Web context. Information \& Management, 38(4), 217-230. doi:10.1016/S0378-7206(00)00061-6

Pechtelidis, Y., Kosma, Y., \& Chronaki, A. (2015). Between a rock and a hard place: Women and computer technology. Gender and Education, 27(2), 164-182. doi:10.1080/09540253.2015.1008421

Rauschnabel, P. A., He, J., \& Ro, Y. K. (2018). Antecedents to the adoption of augmented reality smart glasses: A closer look at privacy risks. Journal of Business Research, 92, 374-384. doi:10.1016/j.jbusres.2018.08.008

Reynolds, N. L., Simintiras, A. C., \& Diamantopoulos, A. (2003). Theoretical justification of sampling choices in international marketing research: Key issues and guidelines for researchers. Journal of International Business Studies, 34(1), 80-89. doi:10.1057/palgrave.jibs.8400000

Rodríguez-Ardura, I., \& Meseguer-Artola, A. (2018). The playfulness of Facebook - Shaped by underlying psychological drivers and gender differences. Telematics and Informatics, 35(8), 2254-2269. doi:10.1016/j. tele.2018.09.004

Rogers, E. M. (2003). Diffusion of innovation (5th ed.). New York: Free press.

Rufin, R., Belanger, F., Molina, C. M., Carter, L., \& Figueroa, J. C. (2014). A Cross-Cultural Comparison of Electronic Government Adoption in Spain and the USA. International Journal of Electronic Government Research, 10(2), 43-59. doi:10.4018/ijegr.2014040104

Sanchez-Franco, M. J. (2006). Exploring the influence of gender on the web usage via partial least squares. Behaviour \& Information Technology, 25(1), 19-36. doi:10.1080/01449290500124536

Schwartz, S. H. (1994). Are there universal aspects in the structure and contents of human values? The Journal of Social Issues, 50(4), 19-45. doi:10.1111/j.1540-4560.1994.tb01196.x 
Skog, B. (2002). Mobiles and the Norwegian Teen: Identity, Gender and Class, Perpetual Contact, Cambridge University Press, 255-273.

Smith, R., Deitz, G., Royne, M. B., Hansen, J. D., Grünhagen, M., \& Witte, C. (2013). Cross-cultural examination of online shopping behavior: A comparison of Norway, Germany, and the United States. Journal of Business Research, 66(3), 328-335. doi:10.1016/j.jbusres.2011.08.013

Strader, T. J., Ramaswami, S. N., \& Houle, P. A. (2007). Perceived network externalities and communication technology acceptance. European Journal of Information Systems, 16(1), 54-65. doi:10.1057/palgrave. ejis.3000657

Sun, H., \& Zhang, P. (2006). The role of moderating factors in user technology acceptance. International Journal of Human-Computer Studies, 64(2), 53-78. doi:10.1016/j.jhcs.2005.04.013

Swoboda, B., \& Hirschmann, J. (2017). Perceptions and effects of cross-national corporate reputation: The role of Hofstede's cultural value approach. International Marketing Review, 34(6), 909-944. doi:10.1108/IMR-082016-0154

Terzis, V., \& Economides, A. A. (2011). Computer based assessment: Gender differences in perceptions and acceptance. Computers in Human Behavior, 27(6), 2108-2122. doi:10.1016/j.chb.2011.06.005

Van Hoorn, A. (2019, March). Generational shifts in managerial values and the coming of a unified business culture: A cross-national analysis using European social survey data. Journal of Business Ethics, 155(2), 547-566. doi:10.1007/s10551-017-3488-4

Venkatesh, V., \& Davis, F. D. (2000). A theoretical extension of the technology acceptance model: Four longitudinal field studies. Management Science, 46(2), 186-204. doi:10.1287/mnsc.46.2.186.11926

Venkatesh, V., \& Morris, M. G. (2000). Why do not men ever stop to ask for direction? Gender, Social influence, and the role in technology acceptance and usage behavior. Management Information Systems Quarterly, 24(1), 115-139. doi:10.2307/3250981

Venkatesh, V., Morris, M. G., Davis, G. B., \& Davis, F. D. (2003). User acceptance of information technology: Toward a unified view. Management Information Systems Quarterly, 27(3), 425-478. doi:10.2307/30036540

Venkatesh, V., Thong, J., \& Xu, X. (2012). Consumer acceptance and user of information technology: Extending the unified theory of acceptance and use of technology. Management Information Systems Quarterly, 36(1), 157-178. doi: $10.2307 / 41410412$

Wagner, N., Hassanein, K., \& Head, M. (2010). Computer use by older adults: A multi-disciplinary review. Computers in Human Behavior, 26(5), 870-882. doi:10.1016/j.chb.2010.03.029

Wang, Q., \& Sun, X. (2016). Investigating gameplay intention of the elderly using an extended Technology Acceptance Model. Technological Forecasting and Social Change, 107, 59-68. doi:10.1016/j.techfore.2015.10.024

Wang, Y., Yu, S., \& Ma, N. (2018). A requirement-scenario-experience framework for evaluating wearable and fashionable design: Presenting underlying factors of user loss. International Journal of Industrial Ergonomics, 68, 137-148. doi:10.1016/j.ergon.2018.07.006

Wu, L.-H., Wu, L.-C., \& Chang, S.-C. (2016). Exploring consumer's intention to accept smartwatch. Computers in Human Behavior, 64, 383-392. doi:10.1016/j.chb.2016.07.005

Zhang, J., Cai, X., Le, T., Fei, W., \& Ma, F. (2019). A Study on Effective Measurement of Search Results from Search Engines. Journal of Global Information Management, 27(1), 196-221. doi:10.4018/JGIM.2019010110

Zhang, M., Luo, M., Nie, R., \& Zhang, Y. (2017). Technical attributes, health attribute, consumer attributes and their roles in adoption intention of healthcare wearable technology. International Journal of Medical Informatics, 108, 97-109. doi:10.1016/j.jmedinf.2017.09.016 PMID:29132639

Zhao, Y., Ni, Q., \& Zhou, R. (2018). What factors influence the mobile health service adoption? A meta-analysis and the moderating role of age. International Journal of Information Management, 43, 342-350. doi:10.1016/j. ijinfomgt.2017.08.006 


\section{ENDNOTES}

https://iot-analytics.com/iot-market-segments-analysis/

https://www.alliedmarketresearch.com/smartwatch-market

https://www.marketresearchfuture.com/reports/smart-watch-market-967

https://www.marketresearchfuture.com/reports/smart-watch-market-967 


\section{APPENDIX A}

Table 2. Items- Reliability abd Convergent validity

\begin{tabular}{|c|c|c|c|c|}
\hline Variable & Items & Loadings & $\begin{array}{l}\text { Alpha } \\
\text { Cronbach }\end{array}$ & AVE \\
\hline \multirow{4}{*}{ PC } & $\begin{array}{l}\text { Most of my colleagues, friends and family members use a } \\
\text { smartwatch }\end{array}$ & 0.896 & 0.896 & 0.763 \\
\hline & $\begin{array}{l}\text { Among the colleagues, friends and family members I } \\
\text { communicate with regularly, many use a smartwatch }\end{array}$ & 0.877 & & \\
\hline & $\begin{array}{l}\text { A large percentage of my colleagues, friends and family } \\
\text { members use a smartwatch }\end{array}$ & 0.900 & & \\
\hline & From my observation, the number of smartwatch users is large & 0.819 & & \\
\hline \multirow{5}{*}{ PU } & $\begin{array}{l}\text { Using my smartwatch helps me connect with others } \\
\text { instantaneously }\end{array}$ & 0.809 & 0.867 & 0.653 \\
\hline & $\begin{array}{l}\text { Using my smartwatch improves the efficiency of my decision } \\
\text { making }\end{array}$ & 0.812 & & \\
\hline & Using my smartwatch increases my productivity & 0.826 & & \\
\hline & $\begin{array}{l}\text { The use of my smartwatch helps me to access to services and } \\
\text { information }\end{array}$ & 0.792 & & \\
\hline & I find my smartwatch to be useful in my work and daily activities & 0.803 & & \\
\hline \multirow{3}{*}{ PEU } & $\begin{array}{l}\text { The usage guidelines of my smartwatch are clear and } \\
\text { understandable }\end{array}$ & 0.864 & 0.821 & 0.736 \\
\hline & The use of my smartwatch does not require a lot of mental effort & 0.828 & & \\
\hline & I find my smartwatch easy to use & 0.880 & & \\
\hline \multirow{4}{*}{ ATU } & Using my smartwatch is a good idea & 0.910 & 0.922 & 0.810 \\
\hline & Using my smartwatch is wise idea & 0.902 & & \\
\hline & I like the idea of using my smartwatch & 0.899 & & \\
\hline & Using my smartwatch is pleasant & 0.889 & & \\
\hline \multirow{4}{*}{ PP } & Using the smartwatch gives enjoyment to me & 0.863 & 0.874 & 0.725 \\
\hline & Using the smartwatch gives fun to me & 0.864 & & \\
\hline & Using the smartwatch keeps me happy & 0.862 & & \\
\hline & Using the smartwatch stimulates my curiosity & 0.817 & & \\
\hline
\end{tabular}




\section{APPENDIX B}

Table 3. Distribution of participants per country

\begin{tabular}{|c|c|c|c|c|c|c|c|c|c|}
\hline Country & \multicolumn{2}{|c|}{ France } & \multicolumn{2}{|c|}{ Germany } & \multicolumn{2}{|c|}{ UK } & \multicolumn{2}{|c|}{ USA } & TOTAL \\
\hline Respondents invited & \multicolumn{2}{|l|}{731} & \multicolumn{2}{|l|}{492} & \multicolumn{2}{|l|}{503} & \multicolumn{2}{|l|}{639} & 2365 \\
\hline Sample collected & \multicolumn{2}{|l|}{300} & \multicolumn{2}{|l|}{297} & \multicolumn{2}{|l|}{297} & \multicolumn{2}{|l|}{303} & 1197 \\
\hline \multirow[t]{2}{*}{ Response Rate } & \multicolumn{2}{|l|}{$41 \%$} & \multicolumn{2}{|l|}{$60 \%$} & \multicolumn{2}{|c|}{$\mathbf{5 9} \%$} & \multicolumn{2}{|l|}{$47 \%$} & $\mathbf{5 1 \%}$ \\
\hline & Nbr & $\%$ & Nbr & $\%$ & Nbr & $\%$ & Nbr & $\%$ & \\
\hline Male & 157 & $52 \%$ & 149 & $50 \%$ & 140 & $47 \%$ & 147 & $49 \%$ & 593 \\
\hline Female & 143 & $48 \%$ & 148 & $50 \%$ & 157 & $53 \%$ & 156 & $51 \%$ & 604 \\
\hline 18-24 years old & 75 & $25 \%$ & 71 & $24 \%$ & 63 & $21 \%$ & 79 & $26 \%$ & 288 \\
\hline $25-34$ years old & 99 & $33 \%$ & 114 & $38 \%$ & 113 & $38 \%$ & 108 & $36 \%$ & 434 \\
\hline $35-44$ years old & 66 & $22 \%$ & 58 & $20 \%$ & 64 & $22 \%$ & 52 & $17 \%$ & 240 \\
\hline $45-56$ years old & 53 & $18 \%$ & 40 & $13 \%$ & 36 & $12 \%$ & 30 & $10 \%$ & 159 \\
\hline 57 plus & 7 & $2 \%$ & 14 & $5 \%$ & 21 & $7 \%$ & 34 & $11 \%$ & 76 \\
\hline
\end{tabular}




\section{APPENDIX C}

Table 4. Discriminant Validity

\begin{tabular}{|l|l|l|l|l|l|}
\hline & \multicolumn{1}{|c|}{ ATU } & \multicolumn{1}{c|}{ PP } & \multicolumn{1}{c|}{ PC } & \multicolumn{1}{c|}{ PEU } & PU \\
\hline ATU & 0.900 & & & & \\
\hline PP & 0.616 & 0.852 & & & \\
\hline PC & 0.458 & 0.391 & 0.874 & & \\
\hline PEU & 0.468 & 0.536 & 0.272 & 0.858 & \\
\hline PU & 0.626 & 0.694 & 0.496 & 0.642 & 0.808 \\
\hline
\end{tabular}




\section{APPENDIX D}

Table 5. OUTER VIF values

\begin{tabular}{|l|l|}
\hline & \\
\hline AT1 & 3.3 \\
\hline AT2 & 3.1 \\
\hline AT3 & 3.1 \\
\hline AT4 & 2.8 \\
\hline PC1 & 3.2 \\
\hline PC2 & 2.5 \\
\hline PC3 & 3.2 \\
\hline PC4 & 1.9 \\
\hline PEU1 & 1.9 \\
\hline PEU2 & 1.7 \\
\hline PEU3 & 2.0 \\
\hline PP4 & 2.3 \\
\hline PP5 & 2.3 \\
\hline PP6 & 2.3 \\
\hline PP7 & 1.9 \\
\hline PU1 & 1.9 \\
\hline PU2 & 2.0 \\
\hline PU3 & 2.1 \\
\hline PU4 & 1.8 \\
\hline PU5 & 1.9 \\
\hline
\end{tabular}

Table 6. INNER VIF values

\begin{tabular}{|l|l|l|l|l|l|}
\hline & \multicolumn{1}{|c|}{ ATU } & PC & PEU & \multicolumn{1}{c|}{ PP } & PU \\
\hline ATU & & & & & \\
\hline PC & 1.3 & & 1.0 & 1.1 & 1.1 \\
\hline PEU & 1.8 & & & 1.1 & 1.1 \\
\hline PP & 2.0 & & & & \\
\hline PU & 2.7 & & & & \\
\hline
\end{tabular}


Patricia Baudier is an associate professor of Marketing at Ecole de Management de Normandie in Paris (France). Her research focuses on new technologies acceptance (Smart home, IoT's, Smart Health...), consumers behavioral and Digital Marketing. She spent 28 years within major American companies such as Apple and Kodak, mainly at marketing positions. She has authored several papers in leading journals of innovation, management and marketing. She co-authored a glossary on digital. She is a program chair of the 2019 FEMIB of Heraklion, an international conference (INSTICC).

Chantal Ammi is a professor in marketing. Chantal has published many articles in the field of information systems and many books as wel.. Chantal is specialized in Innovation and technologies

Samuel Fosso Wamba (HDR) is Full Professor at Toulouse Business School. He earned his Ph.D. in industrial engineering at the Polytechnic School of Montreal, Canada. He has published papers in top journals including: Academy of Management Journal, European Journal of Information Systems, Journal of Cleaner Production, International Journal of Production Economics, International Journal of Production Research, Journal of Business Research, Technology Forecasting and Social Change, Production Planning \& Control. Prof Fosso Wamba is organizing special issues on IT-related topics for leading international journals. According to Google Scholar he has an h-index of 34 and over 4,509 citations by May 6, 2019. Prof Fosso Wamba is CompTIA RFID+ Certified Professional, Academic Co-Founder of RFID Academia. He is the Coordinator of the newly created Artificial Intelligence \& Business Analytics Cluster of Toulouse Business School, France. 